\title{
SISTEM INFORMASI LAYANAN KONSELING BERBASIS BLENDED LEARNING PADA SMK PGRI PEKANBARU
}

\author{
Junadhi'), M. Syaifullah $^{2)}$ \\ ${ }^{1}$ Sistem Informasi, ${ }^{2}$ Teknik Informatika, STMIK Amik Riau \\ Email: junadhi@sar.ac.id ${ }^{1}$
}

\begin{abstract}
Counseling Service Information System based on blended learning is a guidance and counseling service that combines three sources, namely: face to face, offline, and online. This study aims to describe the needs of students for blended counseling services for character development. The system is designed using the PHP programming language and data storage with the MySQL database. The method used in designing this system is the Waterfall model. This system modeling uses the UML (Unified Modeling Language) language. This research was conducted at SMK PGRI Pekanbaru. The results showed that the use of information systems based on blended learning counseling services can shape the character of students that can be developed through a variety of activities and as a form of providing modern counseling services that apply information technology that is not limited to time and place.
\end{abstract}

Keywords: Information Systems, Counseling, Blended Learning

\begin{abstract}
ABSTRAK
Sistem Informasi Layanan Konseling berbasis blended learning adalah layanan bimbingan dan konseling yang mengkombinasikan tiga sumber yaitu: tatap muka, offline, dan online. Penelitian ini bertujuan untuk mendeskripsikan kebutuhan siswa terhadap layanan konseling secara kombinasi (blended) untuk pengembangan karakter. Sistem yang dirancang menggunakan bahasa pemrograman PHP dan penyimpanan data dengan database MySQL. Metode yang digunakan dalam perancangan sistem ini adalah Waterfall model. Pemodelan sistem ini menggunakan bahasa UML (Unified Modelling Language). Penelitian ini dilakukan pada SMK PGRI Pekanbaru. Hasil penelitian menunjukkan bahwa penggunaan sistem informasi layanan konseling berbasis blended learning dapat membentuk karakter siswa yang dapat dikembangkan melalui beragam kegiatan dan sebagai bentuk pemberian layanan konseling modern yang menerapkan teknologi informasi yang tidak terbatas waktu dan tempat.
\end{abstract}

Kata Kunci: Sistem Informasi, Konseling, Blended Learning

\section{PENDAHULUAN}

Bimbingan dan Konseling merupakan bagian dari pendidikan di sekolah, Isi dalam UU Depdiknas RI No.20 Tahun 2013 yaitu pemenuhan kebutuhan siswa untuk saling bergaul sesama teman, guru merupakan salah satu kebutuhan siswa untuk bersosialisasi dan bergaul. Dalam masalah ini, sekolah atau lembaga yang dianggap penting dalam memainkan perannya sebagai tempat belajar bagi siswa, bergaul dan beradaptasi dengan lingkungannya. Dengan demikian sekolah tidak hanya berperan sebagai transformer ilmu pengetahuan, tetapi sekolah juga berperan dalam mengembangkan potensi diri siswa untuk memiliki kekuatan spiritual, keagamaan, pengendalian diri, kepribadian, kecerdasan, akhlak mulia serta ketrampilan yang diperlukan dirinya, masyarakat, bangsa dan negara. Sampai saat ini, layanan bimbingan dan konseling yang dilakukan oleh konselor di Indonesia, masih dilaksanakan secara offline berupa tatap muka di ruang-ruang kelas. Pemanfaatan teknologi informasi dan komputer untuk program konseling, juga belum bisa dilaksanakan konselor secara maksimal (Saputra: 2015). Temuan Efendi \& Naqiyah (2013) menunjukkan bahwa berbagai permasalahan yang muncul dalam konseling antara lain: ada siswa yang merasa tidak nyaman jika konseling dilakukan secara layanan secara face to face, siswa berpandangan bahwa bimbingan dan konseling sekolah sebagai tempat siswa yang bermasalah, keterbatasan waktu guru BK dalam memberikan layanan konseling, rendahnya minat siswa untuk mengikuti layanan bimbingan konseling di sekolah, keterbatasan ruangan media dan pemanfaatan media tambahan sebagai kelengkapan dalam memberikan layanan.

Salah satu terobosan yang perlu dilakukan adalah layanan secara online yang dikemas secara kombinasi (blended) dengan layanan offline yang 
sudah berjalan selama ini. Layanan blended dalam bimbingan dan konseling adalah layanan yang mengkombinasikan keunggulan tiga sumber utama, yaitu: (1) tatap muka, (2) offline, dan (3) online. Media dalam hal ini merupakan alat atau cara yang digunakan sebagai perantara untuk menyampaikan informasi atau pesan, agar dapat diterima oleh penerima informasi sepenuhnya (Dwiyogo, 2013).

\section{KONSELING}

Konseling berasal dari bahasa latin, yaitu consilium yang berarti dengan atau bersama yang dirangkai dengan menerima atau memahami. Sementara dalam bahasa Anglo-Saxon, istilah konseling berasal dari sellan yang berarti menyerahkan atau menyampaikan (Prayitno dan Amti, 2004). Kata konseling mencakup bekerja dengan banyak orang dan hubungannya mungkin saja bersifat pengembangan diri, dukungan terhadap krisis pribadi, psikoterapi, atau pemecahan masalah (British Association of Counselling, 2001 dalam Pieter, 2012).

McLEOD (2010) mengutarakan proses konseling melalui pendekatan "Manajemen Problem" yang disusun dalam tiga tahap utama: membantu klien mengenali dan menjernihkan situasi masalah; mengembangkan program untuk perubahan yang konstruktif; mengimplementasikan target.

Winkel dan Hastuti (2006) menambahkan terdapat lima fase proses konseling dalam kelompok yang meliputi:

1. Pembukaan, dimana diletakkan dasar bagi pengembangan hubungan antarpribadi (working relationship) yang baik, yang memungkinkan pembicaraan terbuka dan terarah pada penyelesaian masalah.

2. Penjelasan masalah, dimana masing-masing konseli mengutarakan masalah yang dihadapi berkaitan dengan masalah diskusi, sambil mengungkapkan fikiran dan perasaaannya secara bebas.

3. Penggalian latar belakang masalah, dimana karena para konseli pada fase dua biasanya belum menyajikan gambaran lengkap mengenai kedudukan masalah dalam keseluruhan situasi hidup masing-masing, diperlukan penjelasan lebih mendetail dan mendalam.

4. Penyelesaian masalah, diakukan berdasarkan apa yang telah digali dalam fase analisis kasus, konselor dan para konseli membahas bagaimana persoalan dapat diatasi.

5. Penutup, bilamana kelompok sudah siap untuk melaksanakan apa yang telah diputuskan bersama. Proses konseling dapat diakhiri dan kelompok dapat dibubarkan pada pertemuan terakhir.

\section{BLENDED LEARNING}

Blended learning adalah sebuah model pembelajaran yang menggabungkan antara pembelajaran tatap muka (face-to-face) dengan $e$ learning. Blended learning merupakan konsep baru dalam pembelajaran dimana penyampaian materi dapat dilakukan di kelas dan online (Bielawski dan Metcalf dalam Husamah 2014). Penggabungan yang dilakukan secara baik antara pengajaran tatap muka dimana pengajar dan pebelajar bertemu langsung dan melalui media online yang bisa diakses kapanpun. Penggabungan pembelajaran tatap muka (face-to-face) dengan e-learning tersebut disebabkan karena terbatasnya waktu dan mudah membuat siswa merasa cepat bosan dalam proses pembelajaran serta tuntutan perkembangan teknologi yang semakin luas.

Blended learning dikembangkan karena kelemahan-kelemahan yang muncul pada pembelajaran tatap muka (face-to-face) dan $e$ learning. Selain dikembangkan karena munculnya kelemahan dari kedua pembelajaran tersebut, blended learning dikembangkan karena kelebihan dari pembelajaran tatap muka (face-to-face) dan $e$ learning. Adapun kelebihan dari blended learning yang diungkapkan oleh Kusairi (dalam Husamah 2014), yaitu:

1. Peserta didik leluasa untuk mempelajari materi pelajaran secara mandiri dengan memanfaatkan materi materi yang tersedia secara online.

2. Peserta didik dapat berkomunikasi/ berdiskusi dengan pengajar atau peserta didik lain yang tidak harus dilakukan saat di kelas (tatap muka)

3. Kegiatan pembelajaran yang dilakukan peserta didik di luar jam tatap muka dapat dikelola dan dikontrol dengan baik oleh pengajar.

4. Pengajar dapat menambahkan materi pengayaan melalui fasilitas internet.

5. Pengajar dapat meminta peserta didik membaca materi atau mengerjakan tes yang dilakukan sebelum pembelajaran

6. Peserta didik dapat saling berbagi file dengan peserta didik lainnya.

\section{METODE PENELITIAN}

Dalam sistem informasi layanan konseling menggunakan metode waterfall yang bekerja dengan sistematis dan terstuktur secara bertahap dalam pembangunan sistem (Boehm, 1988). 


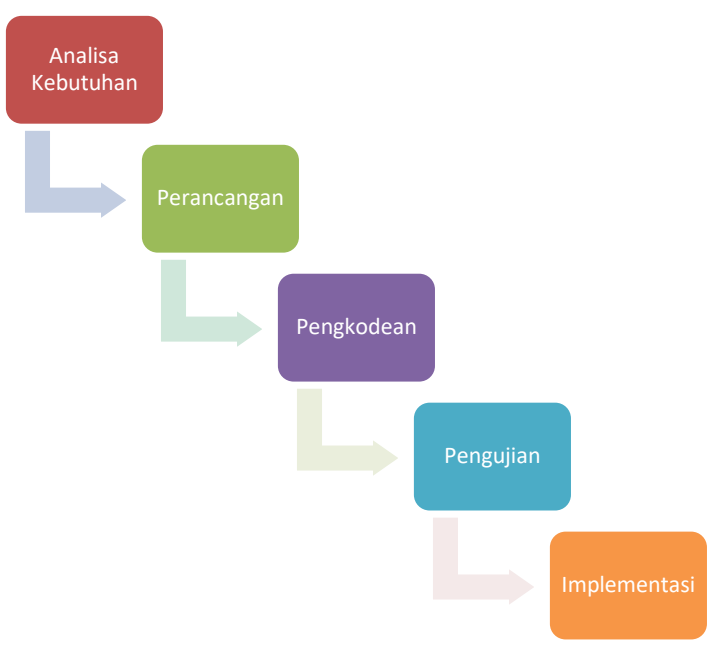

Gambar 1. Model Waterfall

Pada gambar diatas adalah tahapan tahapan dalam pengembanga sistem informasi layanan konseling. Adapun langkah-langkah nya adalah :

1. Analisis Kebutuhan : Langkah awal yang harus dilakukan yaitu menidentifikasi kebutuhankebutuhan apa saja yang dibutuhkan dalam membangun suatu sistem pengolahan data tahanan dan barang bukti dengan cara melakukan observasi dan wawancara.
2. Perancangan : Langkah yang kedua ini terkait perancangan yang akan dibuat dalam pembangunan sistem yang sesuai kebutuhan.

3. Pengkodean : Langkah ke tiga yaitu melakukan pengkodean sistem sesuai dengan perancangan yang dirancang sebelumnya. Pengkodean ini menggunakan bahasa pemograman PHP dan MySQL untuk penyimpanan data.

4. Pengujian : Langkah ke empat yaitu melakukan test atau pengujian terhadap sistem yang telah dibangun agar sesuai dengan yang diharapkan.

5. Implementasi : Langkah yang terakhir yaitu penerapan sistem informasi layanan konseling di SMK PGRI Pekanbaru.

\section{HASIL DAN PEMBAHASAN}

\subsection{Desain Sistem}

Perancangan sistem informasi layanan konselingmdirancang menggunakan alat bantu berupa UML (Unifield Modelling Language) agar mempermudah memindahkan konsep yang dirancang ke dalam bentuk program, dimana perancangannya digambarkan dalam bentuk diagramdiagram berikut:

1. Use Case Diagram

Berikut use case diagram sistem informasi layanan konseling berbasis blended learning dimana, terdapat tiga aktor yaitu Administrator, Guru BK, dan Siswa.

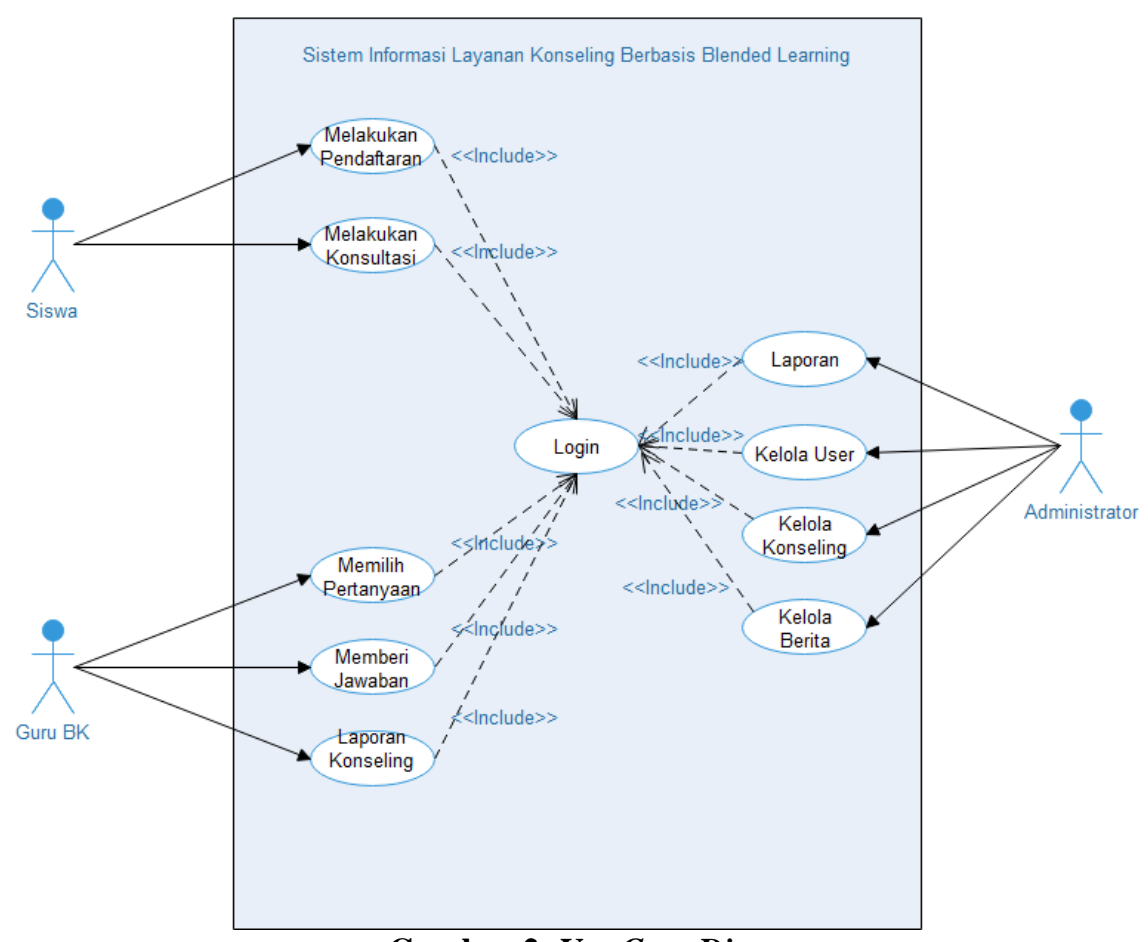

Gambar 2. Use Case Diagram

\section{Activity Diagram}

Activity diagram menggambarkan aktifitas-aktifitas yang dapat dilakukan oleh user didalam sistem informasi layanan konseling. Pada activity diagram di bawah ini dapat kita lihat aktifitas dari user mengakses berbagai halaman seperti mengelola data user, data konseling, data berita, melakukan konseling, memberi jawaban konseling, dan laporan. 
a. Activity Diagram Konseling

Activity diagram konseling ditunjukkan pada gambar 3, dimana user memilih form konseling kemudian mengisi pertanyaan yang diajukan dan jika terjadi perubahan pertanyaan, siswa bisa melakukan update terhadap pertanyaan tersebut.

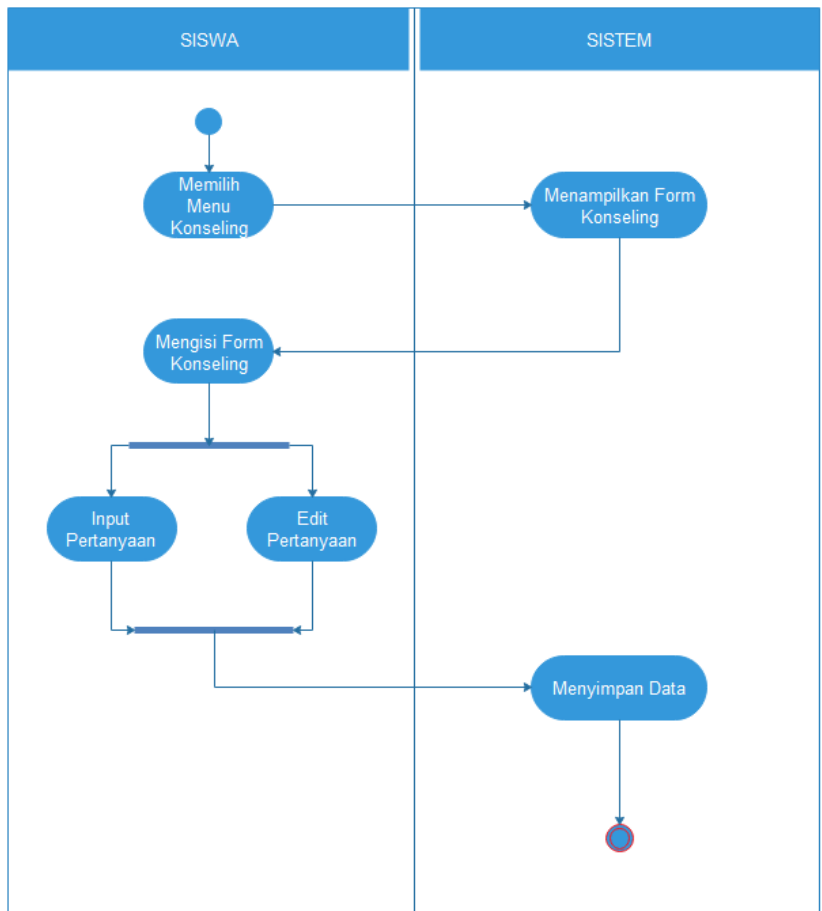

Gambar 3. Activity Diagram Konseling

b. Activity Diagram Jawaban Konseling

Activiti diagram jawaban konseling merupakan kegiatan atau aktifitas yang dilakukan oleh guru BK untuk menjawab pertanyaan yang diajukan oleh siswa. Berikut ini adalah gambarnya.

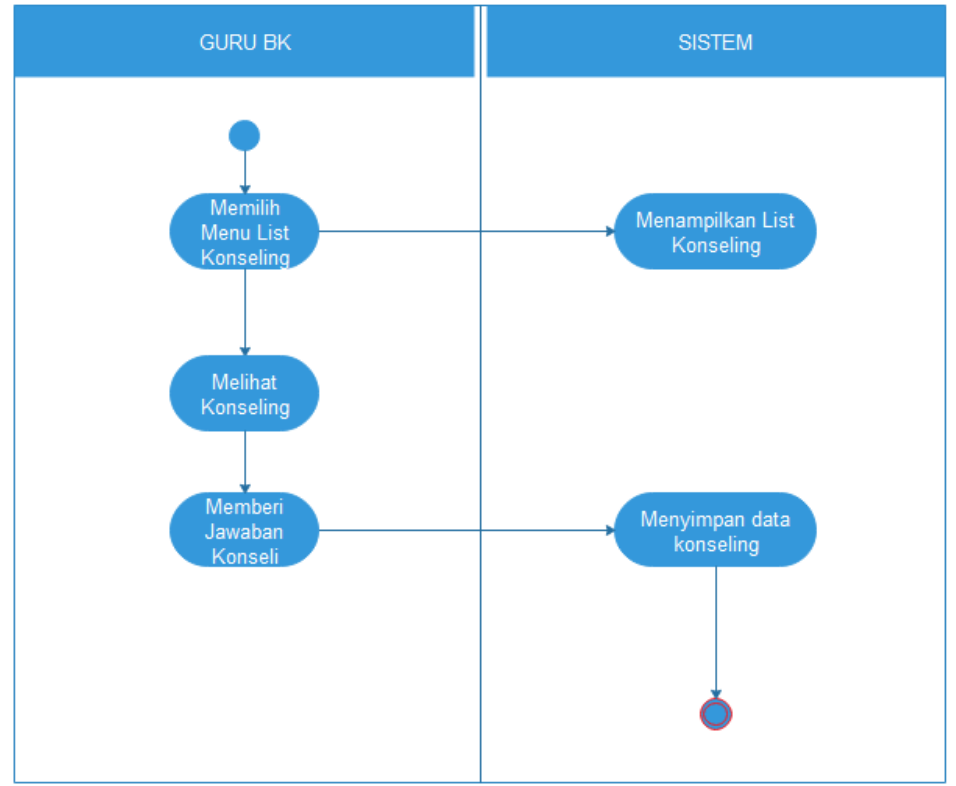

Gambar 4. Activity Diagram Jawaban Konseling 
c. Activity Diagram Laporan Konseling

Activity diagram laporan konseling merupakan layanan yang diakses oleh guru BK dalam mencetak laporan.

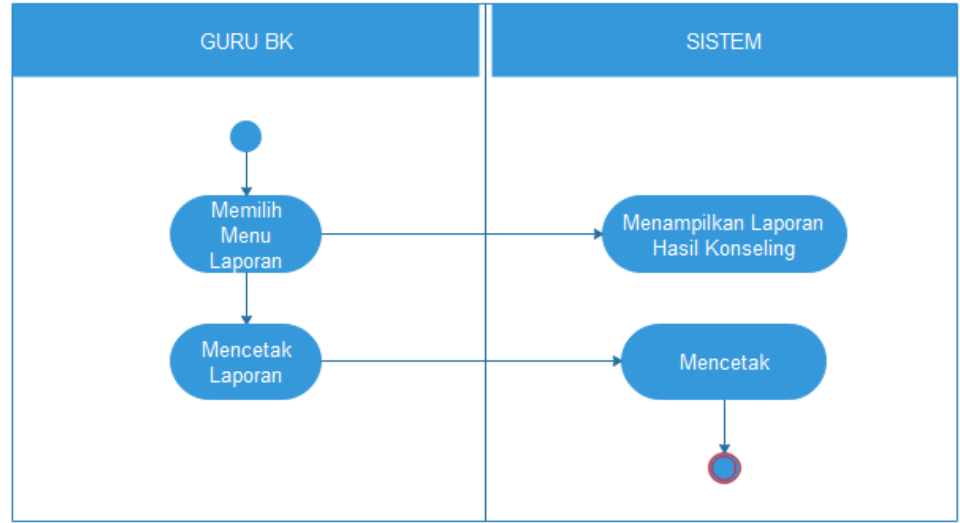

Gambar 5. Activity Diagram Laporan Konseling

d. Activity Diagram Login

Activity diagram login merupakan aktivitas yang dilakukan oleh user sebelum melakukan aksi terhadap sistem yang dibangun.

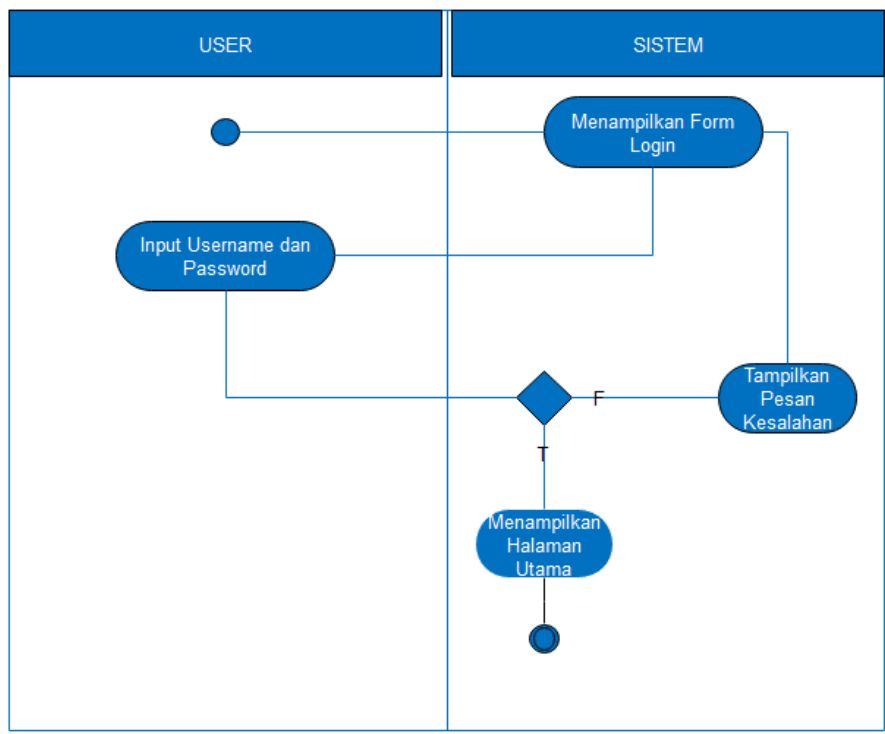

Gambar 6. Activity Diagram Login

3. Sequence Diagram

Sequence diagram ini memperlihatkan tahap demi tahap apa saja yang harus terjadi untuk menghasilkan suatu interaksi di dalam use case diagram.

a. Sequnece Diagram Konseling

Sequence diagram merupakan diagram yang menggambarkan interaksi antar obyek dan mengindikasikan komunikasi diantara obyek-obyek tersebut. Diagram ini juga menunjukkan serangkaian pesan yang dipertukarkan oleh obyek-obyek yang melakukan suatu tugas atau aksi tertentu 


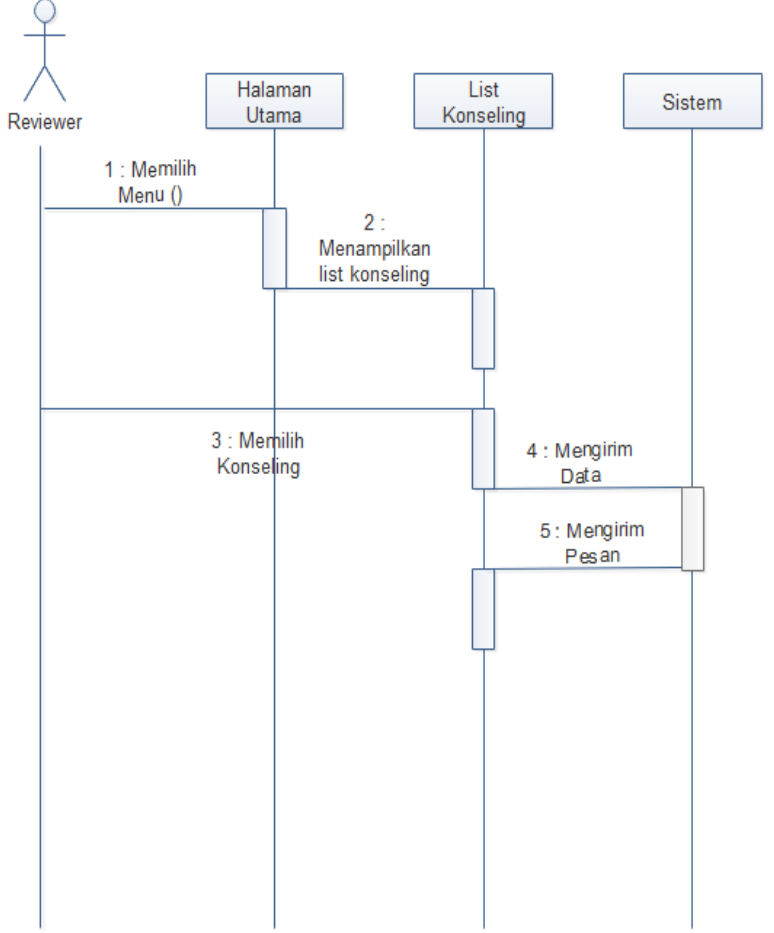

Gambar 7. Sequence Diagram Konseling

b. Sequence Diagram Jawab Konseling

Sequence diagram jawab konseling ditampilkan pada gambar 8 dibawah ini.

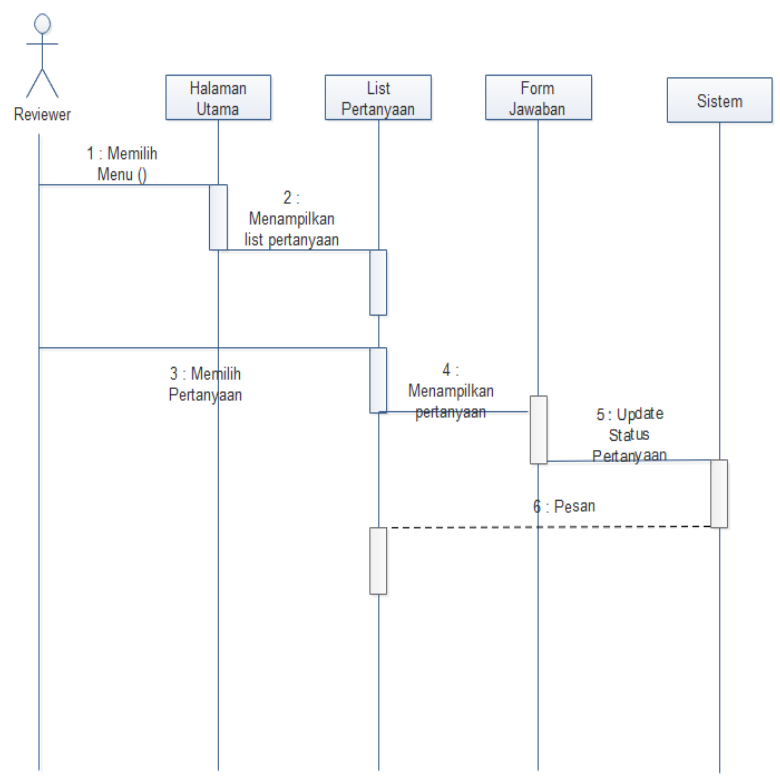

Gambar 8 Sequence Diagram Jawab Konseling c. Sequence Diagram Cetak Laporan

Berikut ini adalah sequence diagram cetak laporan pada sistem yang dibangun.

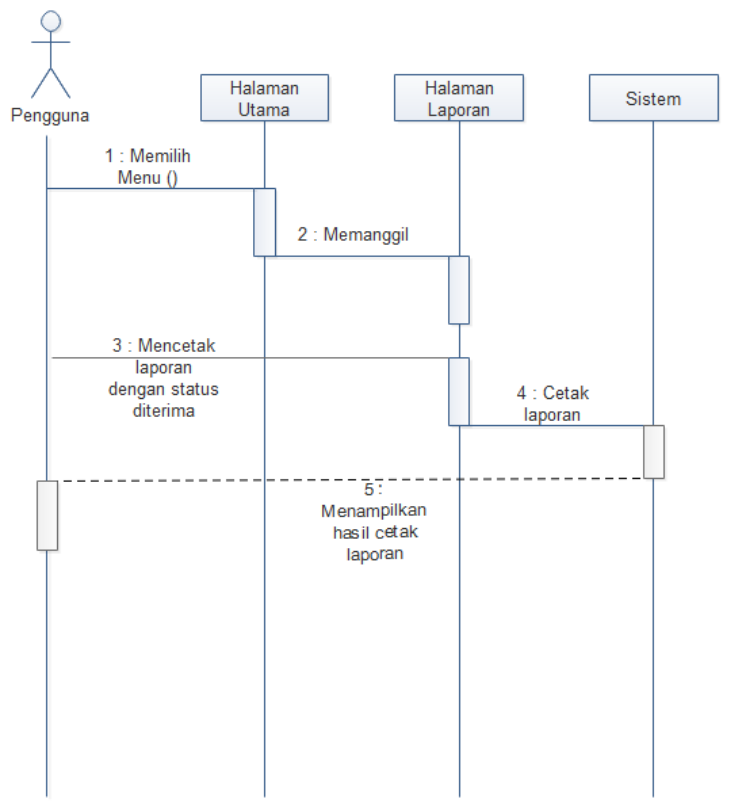

Gambar 9. Sequence Diagram Cetal Laporan

4. Class Diagram

Class diagram merupakan Model statis yang menggambarkan struktur dan deskripsi class serta hubungannya antara class.

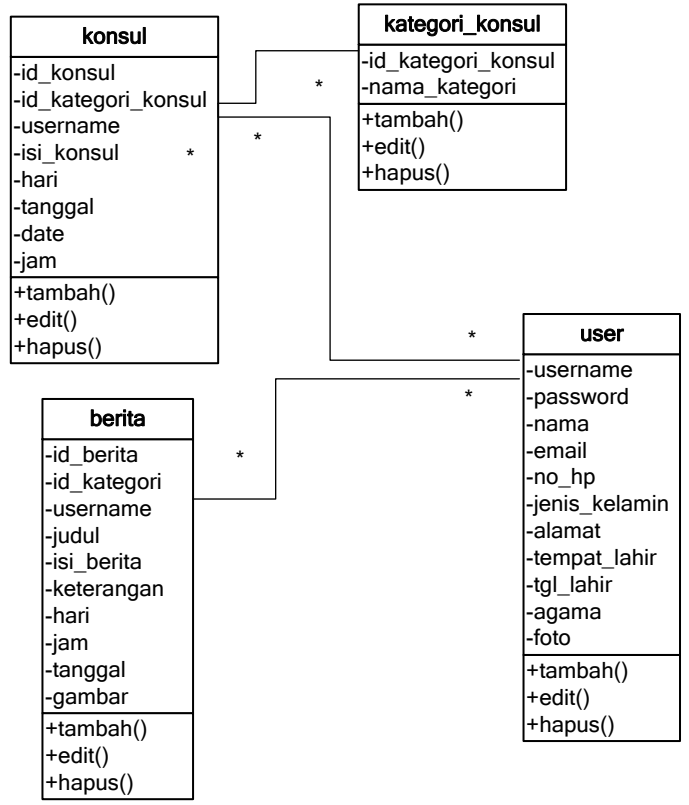

Gambar 9. Class Diagram 


\subsection{Impelementasi Sistem}

1. Tampilan Halaman Utama Sistem Informasi Layanan Konseling

Sistem informasi layanan konseling masih localhost belum di hosting, berikut ini adalah halaman utama saat kita membuka websitenya.

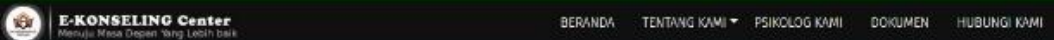

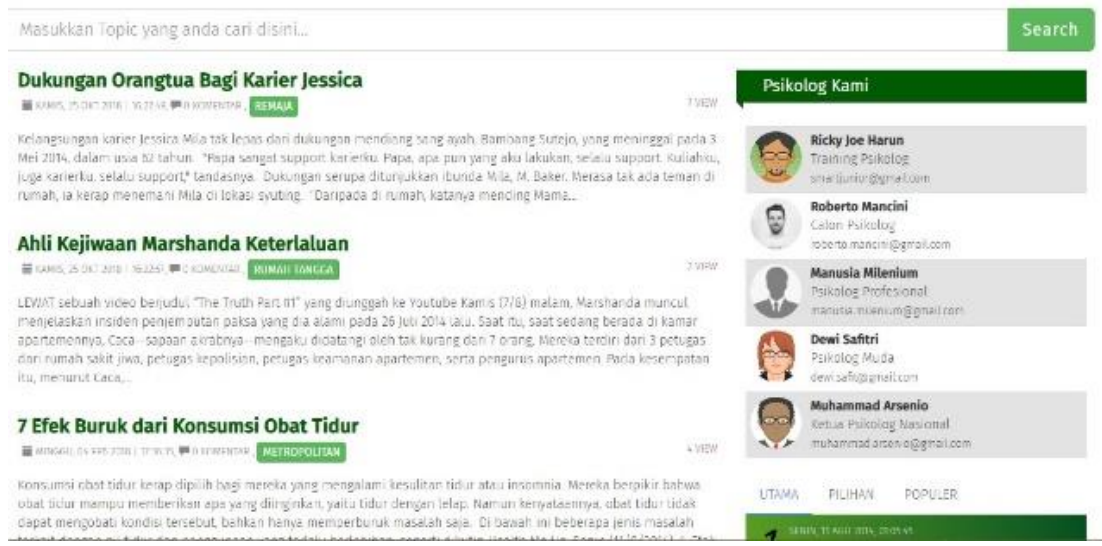

Gambar 2. Tampilan Halaman Utama

2. Tampilan Halaman Daftar

Setiap siswa yang ingin melakukan konseling harus mendaftar, berikut ini adalah halaman untuk pendaftarannya.

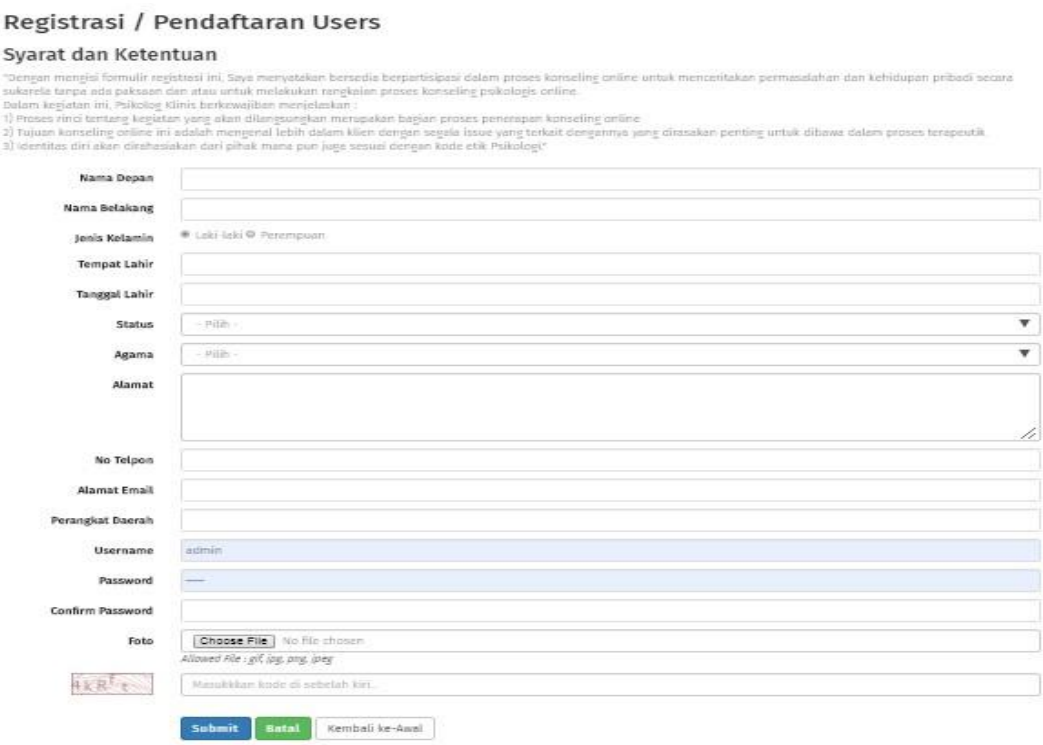

Gambar 3. Tampilan Halaman Pendaftaran 
3. Halaman Login Guru BK

Sebelum menjawab pertanyaan yang diajukan oleh siswa maka, guru BK harus melakukan login terlebih dahulu.

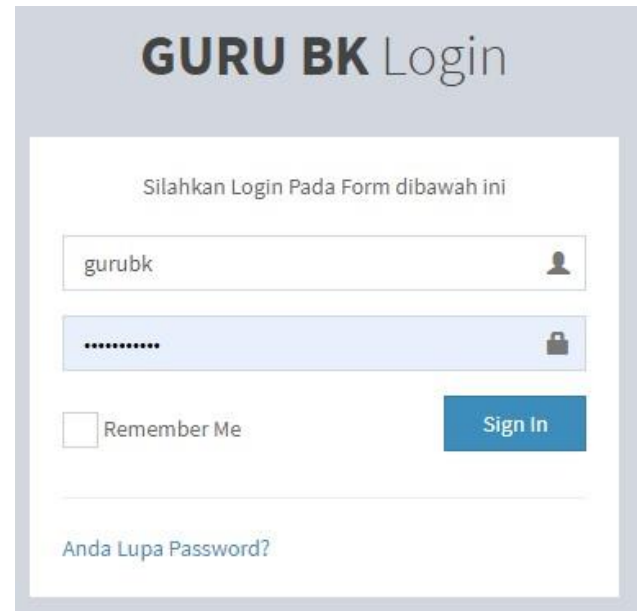

Gambar 4. Tampilan Login Guru BK

4. Halaman Utama Guru BK

Setelah berhasil login maka akan tampil halaman utama yang dapat dilihat pada gambar 5 dibawah ini.

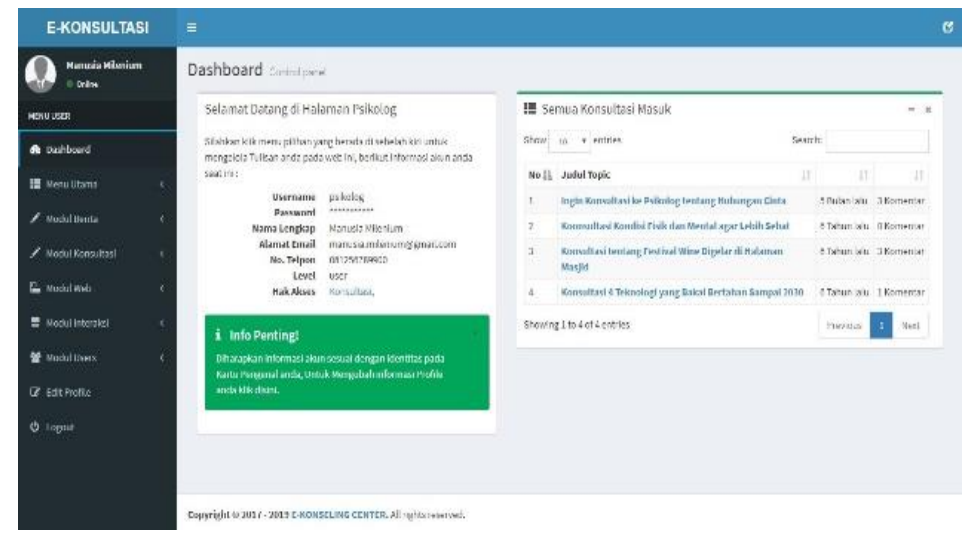

Gambar 5. Tampilan Login Guru BK

5. Halaman Login Adminstrator

Sebelum administrator mengelola sistem informasi layanan konseling maka harus login terlebih dahulu.

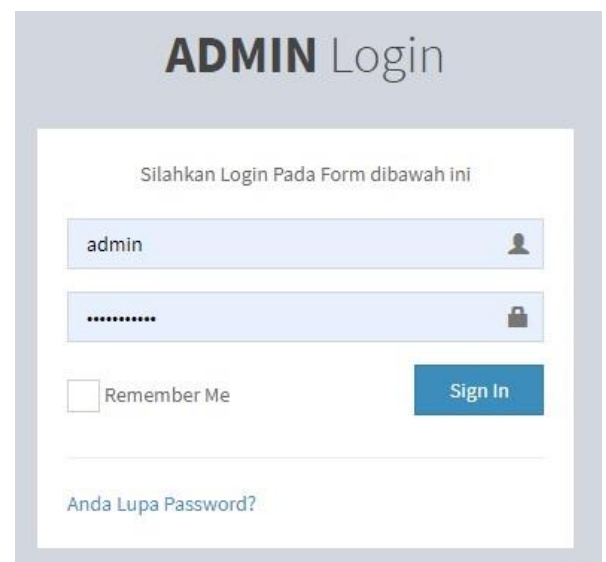

Gambar 6. Halaman Login Administrator 
6. Halaman Utama Admin

Halaman utama admin pada saat telah sukses login ke sistem.

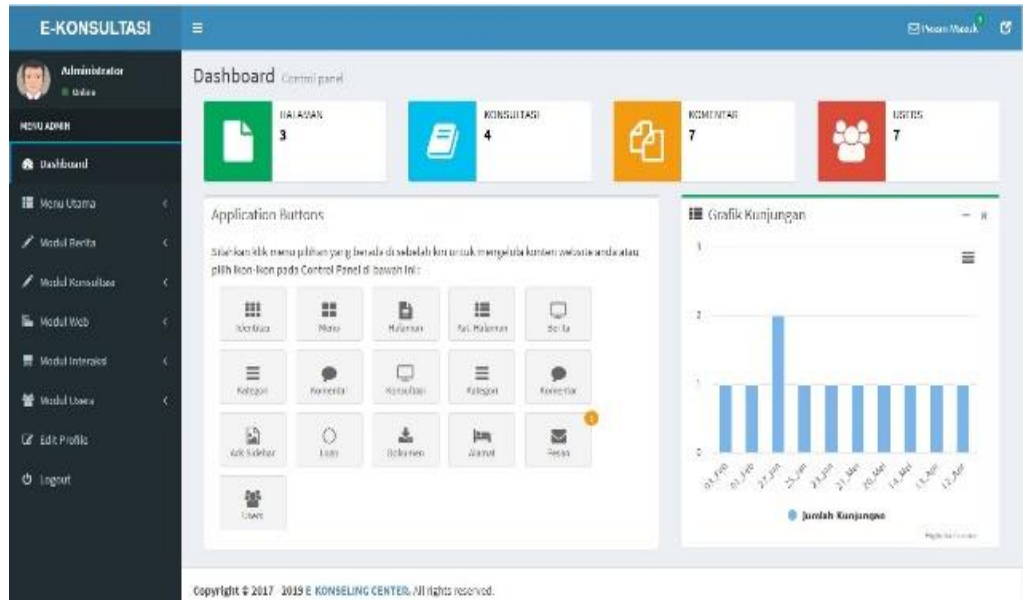

Gambar 7. Halaman Utama Administrator

7. Halaman Kelola User

Halaman ini merupakan user yang terlibat pada sistem informasi layanan konseling yaitu siswa, guru BK, dan administrator

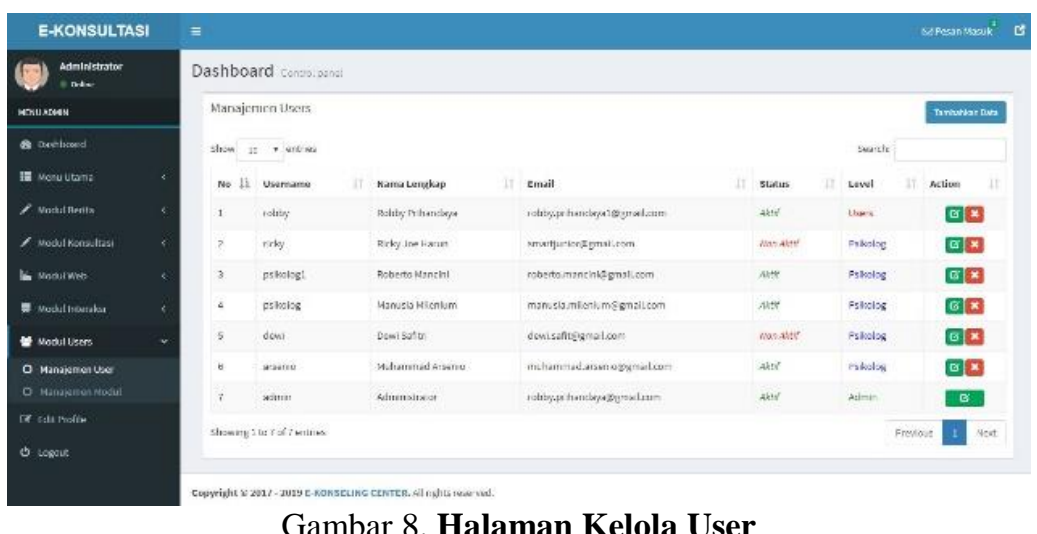

Gambar 8. Halaman Kelola User

8. Halaman Kelola Konseling

Halaman kelola konseling adalah halaman yang menampung daftar pertanyaan dari siswa.

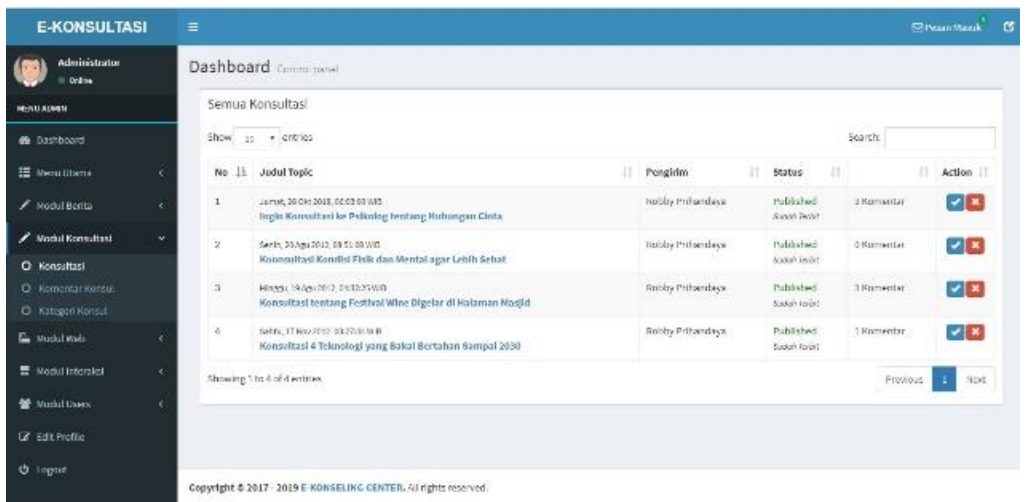

Gambar 9. Halaman Kelola Konseling 


\subsection{Pengujian Sistem}

Dari hasil pengujian yang telah dilakukan menggunakan blackbox maka aplikasi yang dirancang berjalan dengan sesuai harapan, untuk lebih detailnya lihat tabel dibawah ini:

\begin{tabular}{|c|c|c|c|c|}
\hline No & \multicolumn{2}{|c|}{ Komponen Uji } & $\begin{array}{l}\text { Hasil yang } \\
\text { diharapkan }\end{array}$ & Validasi \\
\hline 1 & \multicolumn{2}{|c|}{ Login } & $\begin{array}{l}\text { Dapat masuk } \\
\text { kedalam } \\
\text { sistem sesuai } \\
\text { username dan } \\
\text { password } \\
\text { yang di input }\end{array}$ & Berhasil \\
\hline \multirow[t]{3}{*}{2.} & \multirow[t]{3}{*}{$\begin{array}{l}\text { Siswa - } \\
\text { Menu } \\
\text { Konseling }\end{array}$} & $\begin{array}{c}\text { Tampilan } \\
\text { Form } \\
\text { input } \\
\text { konseling } \\
\end{array}$ & $\begin{array}{l}\text { Menampilkan } \\
\text { form input }\end{array}$ & Berhasil \\
\hline & & Cek Hasil & $\begin{array}{c}\text { Menampilkan } \\
\text { nilai }\end{array}$ & Berhasil \\
\hline & & Proses & $\begin{array}{c}\text { Menampilkan } \\
\text { Grafik Nilai }\end{array}$ & Berhasil \\
\hline 3. & $\begin{array}{c}\text { Mahasiswa } \\
\text { - Menu } \\
\text { Laporan }\end{array}$ & & $\begin{array}{c}\text { Menampilkan } \\
\text { Grafik Nilai }\end{array}$ & Berhasil \\
\hline \multirow[t]{2}{*}{4.} & \multirow[t]{2}{*}{$\begin{array}{c}\text { Guru - } \\
\text { Menu Data } \\
\text { Siswa } \\
\end{array}$} & $\begin{array}{c}\text { Tampilan } \\
\text { list data } \\
\text { siswa } \\
\end{array}$ & $\begin{array}{c}\text { Menampilkan } \\
\text { Data list } \\
\text { siswa }\end{array}$ & Berhasil \\
\hline & & $\begin{array}{l}\text { Button } \\
\text { Lihat }\end{array}$ & $\begin{array}{c}\text { Memproses } \\
\text { data siswa } \\
\text { yang } \\
\text { melakukan } \\
\text { konseling }\end{array}$ & Berhasil \\
\hline \multirow[t]{4}{*}{5.} & \multirow[t]{4}{*}{$\begin{array}{c}\text { Admin - } \\
\text { Menu Data } \\
\text { Guru }\end{array}$} & $\begin{array}{c}\text { Tampilan } \\
\text { List data } \\
\text { seluruh } \\
\text { guru }\end{array}$ & $\begin{array}{c}\text { Menampilkan } \\
\text { seluruh list } \\
\text { data guru }\end{array}$ & Berhasil \\
\hline & & $\begin{array}{l}\text { Button } \\
\text { tambah }\end{array}$ & $\begin{array}{c}\text { Menampilkan } \\
\text { Form Input } \\
\text { Data Guru } \\
\end{array}$ & Berhasil \\
\hline & & $\begin{array}{c}\text { Button } \\
\text { Edit }\end{array}$ & $\begin{array}{c}\text { Menampilkan } \\
\text { Form Edit } \\
\text { Data Guru }\end{array}$ & Berhasil \\
\hline & & $\begin{array}{l}\text { Button } \\
\text { Hapus }\end{array}$ & $\begin{array}{c}\text { Menghapus } \\
\text { Data Guru }\end{array}$ & Berhasil \\
\hline 6. & $\begin{array}{c}\text { Admin - } \\
\text { Menu Data } \\
\text { Siswa }\end{array}$ & $\begin{array}{c}\text { Tampilan } \\
\text { Data } \\
\text { seluruh } \\
\text { Siswa }\end{array}$ & $\begin{array}{c}\text { Menampilkan } \\
\text { list Data } \\
\text { Siswa }\end{array}$ & Berhasil \\
\hline 7 & $\begin{array}{c}\text { Admin - } \\
\text { Menu } \\
\text { Konseling }\end{array}$ & $\begin{array}{c}\text { Tampilan } \\
\text { Proses } \\
\text { Konseling }\end{array}$ & $\begin{array}{c}\text { Menampilkan } \\
\text { proses } \\
\text { konseling } \\
\end{array}$ & Berhasil \\
\hline
\end{tabular}

\section{KESIMPULAN}

Dari uraian dan penjelasan yang telah dikemukakan pada bab-bab sebelumnya, maka dapat ditarik kesimpulan dari penelitian yang telah dilakukan dan saran-saran yang diharapkan bermanfaat bagi pembaca pada umumnya dan bagi pihak yang bersangkutan. Kesimpulan yang dapat dikemukakan antara lain:

1. Melalui rancangan sistem informasi pelayanan konseling berbasis blended learning, diharapkan proses pembentukan karakter dapat dikembangkan dan ditegakkan melalui beragam kegiatan.

2. Dengan adanya sistem informasi pelayanan konseling ini dapat digunakan sebagai bentuk pemberian layanan konseling modern yang menerapkan teknologi informasi yang tidak terbatas waktu dan tempat.

\section{DAFTAR PUSTAKA}

Boehm, B.W., (1988). A spiral model of software development and enhancement. Computer, 21(5):61-72.

Dwiyogo, W.D. 2013. Media Pembelajaran. Malang: Wineka Media.

Efendi, M., \& Naqiyah, N (2013). Pengembangan Media Blog Dalam Layanan Informasi Bimbingan Dan Konseling. Jurnal Mahasiswa Teknologi Pendidikan, 1(1), 1-20.

Husamah. (2014). Pembelajaran Bauran (Blended Learning) Terampil Memadukan Keunggulan Pembelajaran Face-To-Face, E-learning Offline-Online, dan Mobile Learning. Jakarta: Prestasi Pustaka.

McLeod, John. (2010). Counsellor's Workbook Developing a Personal Approach. The Second Edition. New York: Open University Press.

Pieter, H.Z. (2012). Pengantar Komunikasi dan Konseling dalam Praktik Kebidanan. Suatu Kajian Psikologi. Jakarta: Kencana Prenada Media Group.

Prayitno dan Amti. (2004). Pelayanan Bimbingan dan Konseling Sekolah Menengah Kejuruan $(S M K)$. Jakarta: Kerjasama Koperasi Karyawan Pusgrafin dengan Penerbit Penebar Aksara.

Saputra, W. N. E. (2015). Evaluasi Program Konseling di SMP Kota Malang: Discrepancy Model. Jurnal Psikologi Pendidikan dan Konseling, 1(2), 180-187.

Winkel, W.S \& Sri Hastuti. (2006). Bimbingan dan Konseling di Institusi Pendidikan. Jakarta: PT. Grasindo. 